\title{
On the Loss of Injectant and Apparent Dispersivity in Single-Well Push-Pull Tests Influenced by Natural Drift
}

\author{
Sverre G. Johnsen • Curtis H. Whitson
}

Received: 1 March 2010 / Accepted: 20 July 2010 / Published online: 4 August 2010

(C) The Author(s) 2010. This article is published with open access at Springerlink.com

\begin{abstract}
In a previous article, a semi-analytical stream-line based model was developed for single-well push-pull tests in stratified reservoirs subject to natural drift. Based on that model, this article gives the theoretical maximum injection phase duration giving conservative injectant production, in a single-layer reservoir with natural drift. In addition, an analytical expression for the single-layer apparent dispersivity due to natural drift is given. Finally, it is shown how the large-scale apparent dispersivities observed in experimental data from a stratified aquifer may be predicted by constructing a production profile using the estimated single-layer apparent dispersivities.
\end{abstract}

Keywords Apparent dispersivity · Lost injectant · Natural drift · Push-pull echo test

\section{Introduction}

Push-pull tests are single-well tests where an injection phase (push) is followed by a production phase (pull). Injectant concentrations in the producing liquid are measured during the production phase, giving the push-pull production profile. In a Ph.D. thesis from NTNU, Johnsen (2007), and a previous article, Johnsen and Whitson (2009), we developed a semianalytical stream-line-based model for single-well push-pull tests performed in stratified reservoirs subject to natural drift. Comparing the model to experimental field data obtained by Pickens and Grisak (1981), it gave an excellent match with no parameter fitting, putting in known test parameters and test site properties, only. The model is free of physical and numerical dispersion, and it was concluded that the large apparent dispersivities, as reported by Pickens and Grisak, could be to a large extent due to natural ground-water drift. We refer

S. G. Johnsen ( $\square)$

SINTEF Materials and Chemistry, Trondheim, Norway

e-mail: sverregu@gmail.com

C. H. Whitson

The Norwegian University of Science and Technology and Pera AS, Trondheim, Norway 
to Johnsen and Whitson (2009) for details on the derivations and nomenclature of the model. Coats et al. (2004) give an extensive literature review and a thorough list of definitions.

Single-well push-pull test dispersivities are commonly assessed by fitting the Aronofsky and Heller (1957)/Gelhar and Collins (1971) analytical solution of the 1D convectiondispersion equation,

$$
C_{\mathrm{CD}}\left(\mathrm{PV}_{\mathrm{inj}}\right)=\frac{1}{2} \operatorname{erfc}\left(\frac{1-\mathrm{PV}_{\mathrm{inj}}}{2 \sqrt{\mathrm{PV}}}\right)+\frac{e^{N_{\mathrm{Pe}} / N_{\mathrm{Pe}}}}{2} \operatorname{erfc}\left(\frac{1+\mathrm{PV}_{\mathrm{inj}}}{2 \sqrt{\mathrm{PV}_{\mathrm{inj}} / N_{\mathrm{Pe}}}}\right),
$$

to the measured push-pull production profile. The apparent dispersivity is defined by $\alpha_{\mathrm{a}}=$ $L / N_{\mathrm{Pe}}$, where the Peclet number, $N_{\mathrm{Pe}}$, is the fitting parameter of Eq. 1 , and the average travel length is given by $L=2\left(\sqrt{2 Q_{\mathrm{i}} T_{\mathrm{i}}+r_{\mathrm{w}}^{2}}-r_{\mathrm{w}}\right)$, where $Q_{\mathrm{i}}$ is the areal injection rate, defined as the volumetric injection rate divided by height, $T_{\mathrm{i}}$ is the injection phase duration, and $r_{\mathrm{W}}$ is the well radius. erfc () is the complementary error function, and the pore-volume injected is related to the dimensionless volume produced by $\mathrm{PV}_{\mathrm{inj}}=\frac{1}{2}\left(\frac{V_{\text {prod }}}{V_{\text {inj }}}+1\right)$.

In this article, we first present an analytical expression for the maximum injection phase duration giving conservative injectant production (all the injectant is recoverable), in a single-layer push-pull test. Secondly, based on the results from the Johnsen and Whitson (2009) model, an estimate for the apparent dispersivity due to natural drift, depending on known test parameters, is presented. Finally, the estimated single-layer apparent dispersivities are employed, to predict the Pickens-Grisak stratified push-pull test production profiles. The predictions support our previous conclusion that "Natural drift alone is enough to cause a large part of the apparent dispersivity reported by Pickens and Grisak."

\section{Loosing Injectant Due to Natural Drift}

The Johnsen-Whitson model is based on the classical source/sink in a uniform stream approach. The combined flow pattern of the radial flow to a sink and the uniform natural drift consists of two separate regions, as shown in Fig. 2b in Johnsen and Whitson (2009). During the injection-phase, injectant is free to cross the production-phase two-region boundary, and it can be shown, Johnsen (2007), that injectant will first cross the boundary at the production-phase stagnation point. In a 2D Cartesian coordinate system, where the source/sink is located in the origin and the uniform flow is in the $\mathrm{x}$-axis direction, the stagnation point is located in $(x, y)=\left(-\frac{Q_{\mathrm{p}}}{U_{\mathrm{u}}}, 0\right)$. Furthermore, it can be shown that the time needed for the first injectant to reach this point is given by

$$
T_{\mathrm{c}}=-\frac{1}{U_{\mathrm{u}}^{2}}\left(Q_{\mathrm{p}}+U_{\mathrm{u}} r_{\mathrm{w}}-Q_{\mathrm{i}} \ln \left|\frac{U_{\mathrm{u}} r_{\mathrm{w}}+Q_{\mathrm{i}}}{Q_{\mathrm{i}}-Q_{\mathrm{p}}}\right|\right) .
$$

The production rate, $Q_{\mathrm{p}}$, is negative, per definition, and the injection rate, $Q_{\mathrm{i}}$, and the natural drift velocity, $U_{\mathrm{u}}$, are positive. Liquid at the down-stream side of the boundary is not recoverable unless the production rate is increased; thus if $T_{\mathrm{i}}>T_{\mathrm{c}}$, then some of the injectant will be lost. The closer the injection phase duration is to the cirtical time, the more pronounced the production profile tailing will be. For a stratified reservoir, the critical time will, in general, be different for each stratum. Thus, production might be conservative in some strata, while injectant is lost in others. 


\section{The Apparent Dispersivity Due to Natural Drift}

Figure 1 shows the Eq. 1 best-fit Peclet numbers for a 1,000 single-layer production profiles, obtained from the Johnsen-Whitson model with a 1000 stream-lines, using independent random test parameters. Each stream-line is responsible for one point in the production profile, so that the best-fit Peclet numbers were obtained from fitting Eq. 1 to a 1,000 points, employing the least-squares method. The test parameters were taken from a log-uniform distribution across the interval $[0.1 \beta, 10 \beta]$, where $\beta \in\left\{Q_{\mathrm{i}}, Q_{\mathrm{p}}, U_{\mathrm{u}}\right\}$ is the Pickens-Grisak SW1 test parameter value. Injection/production rate combinations where one was more than ten times the other were, however, not accepted. The injection phase duration was taken from a $\log$-uniform distribution across the interval $\left[0.01 T_{\mathrm{c}}, T_{\mathrm{c}}\right]$. Obtaining best-fit apparent Peclet numbers for $T_{\mathrm{i}}>T_{\mathrm{c}}$ makes no sense, since employing Eq. 1 requires conservative injectant production. As is illustrated in Fig. 1, the best-fit single-layer Peclet numbers, due to natural drift alone, follow a linear trend:

$$
N_{\mathrm{Pe}} \approx 7.5 \cdot\left(T_{\mathrm{i}} / T_{\mathrm{c}}\right)^{-1}\left(Q_{\mathrm{i}} / Q_{\mathrm{p}}\right)^{0.6},
$$

with an uncertainty of approximately $\pm 30 \%$. In our model, there is no physical or numerical dispersion, and so the single-layer apparent dispersivity due to natural drift alone can be estimated by

$$
\alpha_{\mathrm{a}} \approx 0.13 L\left(T_{\mathrm{i}} / T_{\mathrm{c}}\right)\left(Q_{\mathrm{i}} / Q_{\mathrm{p}}\right)^{-0.6},
$$

which plots linearly versus travel-length, on a log-log scale, as expected from the literature, Arya et al. (1988).

For a stratified reservoir, the producing injectant concentration is a combination of the injectant production rates from each stratum, in accordance with Muskat (1949), as shown in Eq. 28 of Johnsen and Whitson (2009),

$$
C=\sum_{j}\left(C_{j} b_{j} k_{j}\right) /\left(b k_{A}\right),
$$

where $C$ is the over-all producing injectant concentration, depending on the volume produced, $b$ is the height, and $k$ is the permeability. $j$ denotes layer properties, and $A$ denotes an arithmetic average. Assuming that the $C_{j}$ are given by Eq. 1, with Peclet numbers given by Eq. 3, it is possible to predict the over-all production profile from Eq. 5. In Fig. 2, the

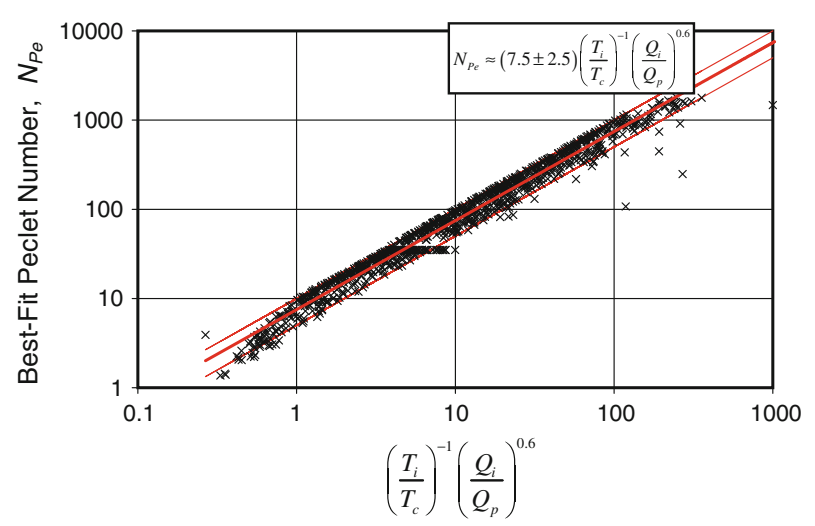

Fig. 1 Push-pull test best-fit single-layer Peclet numbers, for random test parameters (x), vs. $\left(T_{i} / T_{C}\right)^{-1}\left(Q_{i} / Q_{p}\right)^{0.6}$ shown with a best-fit trend-line $(-)$ 


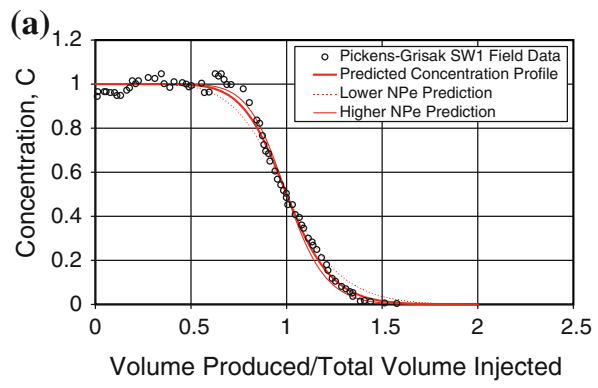

SW1

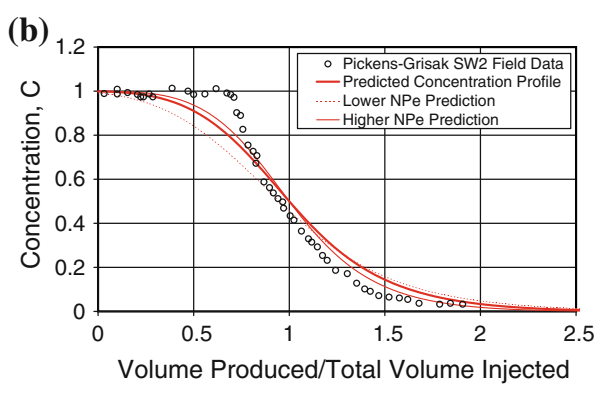

SW2

Fig. 2 Pickens-Grisak experimental field data compared to predicted push-pull production profiles based on Eq. 5 and Peclet number estimations, using Eq. 3 for each layer. High/low $( \pm 30 \%)$ Peclet number estimates are used for the thin curves

Pickens-Grisak experimental data are shown along with the Eq. 3 predicted profiles, together with high/low Peclet number estimates. It is noticed that the uncertainty in the Peclet number estimates are not significant in predicting the Pickens-Grisak experimental data.

\section{Conclusions}

(1) For injection phase durations, $T_{\mathrm{i}}$, larger than some critical time, $T_{\mathrm{c}}$, the tracer production is not conservative, and some injectant is lost.

(2) An analytical expression is given for the best-fit single-layer apparent dispersivity due to natural drift alone.

(3) Experimental field data and their best-fit apparent dispersivities are predicted by following a layer-by-layer summation of production profiles obtained from layerwise Peclet number estimations.

(4) It has been shown that macro-scale best-fit apparent dispersivities do not necessarily signify large-scale in situ mixing of injectant and native liquids.

Open Access This article is distributed under the terms of the Creative Commons Attribution Noncommercial License which permits any noncommercial use, distribution, and reproduction in any medium, provided the original author(s) and source are credited.

\section{References}

Aronofsky, J.S., Heller, J.P.: A diffusion model to explain mixing of flowing miscible fluids in porous media. Trans. AIME. 210, 345-349 (1957)

Arya, A., Hewett, T.A., Larson, R.G., Lake, L.W.: Dispersion and reservoir heterogeneity. SPERE. 3, 139-148 (1988), SPE 14364

Coats, K.H., Whitson, C.H., Thomas, L.K.: Modelling conformance as dispersion. SPE Annual Technical Conference and Exhibition, Houston, Texas, 26-29 September 2004, SPE 90390

Gelhar, L.W., Collins, M.A.: General analysis of longitudinal dispersion in nonuniform flow. Water Resour. Res. 7(6), 1511-1521 (1971)

Johnsen, S.G.: An analytical mathematical theoretical study of single-well push-pull echo tests. PhD Thesis, The Norwegian University of Science and Technology. http://urn.ub.uu.se/resolve?urn=urn:nbn:no:ntnu: diva-1768 (2007)

Johnsen, S.G., Whitson, C.H.: Analytical treatment of a push-pull "echo" test. Transp. Porous Media 77, 399-415 (2009)

Muskat, M.: Effect of permeability stratification in cycling operations. Trans. AIME. 179, 313-328 (1949)

Pickens, J.F., Grisak, G.E.: Scale-dependent dispersion in a stratified granular aquifer. Water Resour. Res. 17(4), 1191-1211 (1981) 